\title{
Assessment of the Potential Use of Hydroponic Effluents for Fodder Production
}

\author{
Prathima Seechurn ${ }^{1}$ and Bhanooduth Lalljee ${ }^{2}$ \\ 1. Department of Agriculture, University of Mauritius, Reduit, +230, Mauritius \\ 2. Department of Agriculture, University of Mauritius, Reduit, +230, Mauritius
}

\begin{abstract}
The performance of Guatemala grass (Tripsacum laxum) under fertigation using hydroponic effluents at different dilution rates (effluent:water: 4:0, 3:1, 1:1, 1:3, 0:4) was compared to fertilisation using farmers' fertiliser rate of 475 $\mathrm{kg}$ 17:8:25/ha applied at planting + $235 \mathrm{~kg}$ Sulphate of Ammonia/ha applied as top dressing one month after and $150 \mathrm{~kg}$ 17:8:25/ha applied after each harvest. Yield response obtained in plots fertilised using undiluted hydroponic effluents was $16.7 \%$ lower than that recorded in plots fertilised using farmers' fertiliser rate. The study showed that there-is potential for using hydroponic effluents (undiluted or diluted in the ratio of $3 \mathrm{HE}$ : 1 water) in fodder production as it can provide sustainable yield in the range of 39.5-41.7 t/ha per harvest. Moreover, dilution rate of hydroponic effluents has a direct impact on crop development and fresh biomass yield. Fodder crop yield responded negatively to the increase dilution of hydroponic effluents from 4HE: 0 water to $3 \mathrm{HE}$ : 1 water, $1 \mathrm{HE}$ : 1 water and $1 \mathrm{HE}$ : 3 water. Consequently, the use of hydroponic effluents can eventually help to save on mineral fertiliser use and reduce cost of production while at the same time address environmental hazards related to hydroponic effluents disposal.
\end{abstract}

Key words: Performance, hydroponic effluents, environmental hazards.

\section{Introduction}

Reducing agricultural water use while maintaining or improving economic productivity of the agricultural sector is a major challenge [1]. Nevertheless, the use of wastewater in agriculture is increasing due to water scarcity and population growth [2]. Wastewater reuse in agriculture represents a potentially important alternative for fresh water thereby saving it for drinking and industry water supplies [3]. However, the use of wastewater in agriculture needs to be done with precautions to avoid harming the agricultural soils and to prevent any consumer health risk. Therefore, methods and technologies that can contribute to improve water use efficiency and productivity merit closer consideration like the use of hydroponic effluents in crop production. In this study, the use of wastewater from hydroponic cultures was largely limited to irrigation of forages only [4].

Corresponding author: Prathima Seechurn, assistant research scientist, main research field: sustainable agriculture and environment. E-mail: babysah@yahoo.com.
Wastewater is indeed an indispensable non-conventional water resource which is increasingly used as an essential alternative for limited freshwater resources [5]. One of the benefits is plant's uptake of water nutrients and therefore a reduction in pollution load which wastewater contributes to surface water supply [6] as well as reduction in use of synthetic inorganic fertilizers [5].

Historically, Mauritius has been depending heavily on sugar production and exports, but currently the sugar sector is under pressure. For many years, the EU sugar regime has favoured Mauritius sugar producers with huge prices. However, now the Mauritius sugar producers have to compete on the global market. As a result, there is a shift away from sugar. At the same time, government policy is attempting to bring the country nearer to self-sufficiency in the food production sector. Land released by reduction in sugar production is being used for crops and livestockrearing. The livestock sector is one which offers great potential for new Small and Medium Enterprises (SMEs) and due to inflation, Mauritius 
have already back peddled towards traditional culture values. The livestock sector is currently rising into prominence and a huge response is being received by the Food and Agricultural Research and Extension Institute towards the enhancement of livestock rearing into SME development [7].

With urbanisation and changing climate, one of the constraints to improve livestock production in Mauritius is the scarcity of quality of feed resources such as grasses/forage and the low productivity of pasture land. Given the limited land resources for pasture development, the government policy is to provide incentive for farmers to invest in intensive fodder production to meet the feed requirement of the growing livestock industry [7].

Under the Food Security Fund project [7], Government policy has been to increase self sufficiency in the production of fresh milk and meat. However, the prerequisite for boosting the local dairy and meat production sector is to encourage production of feed (fodder). Sustainable quality fodder production requires inputs in terms of water and nutrients. Hence the purpose of this project was to investigate the potential of using the hydroponic effluents as a source of nutrients for forage production.

\section{Methodology}

The performance of Guatemala grass was evaluated under fertigation using hydroponic effluents at different dilution rates (hydroponic effluents: water-4:0, 3:1, 1:1, 1:3, 0:4). A treatment using farmers' fertiliser practice of $475 \mathrm{~kg}$ 17:8:25/ha applied as basal treatment and $235 \mathrm{~kg}$ Sulphate of Ammonia/ha applied as top dressing followed by 150 $\mathrm{kg}$ of 17:8:25 applied after each harvest [8] were included in the experiment for comparison purposes.

The 6 treatments were as follows:

T1: Fertigation using undiluted Hydroponic effluents (4 HE: O Water)

T2: Fertigation using diluted hydroponic effluents
(3 HE: 1 Water )

T3: Fertigation using diluted hydroponic effluents 1 HE: 1 Water

T4: Fertigation using diluted hydroponic effluents 1 HE: 3 Water

T5: Farmers fertiliser practice

T6: Water only (O HE: 4Water)

Guatemala crop was established using cuttings of 3 nodes planted $40 \mathrm{~cm}$ within the row spaced $75 \mathrm{~cm}$ apart. The plot treated with farmers fertiliser practice (T5) was irrigated using drip system and received same volume of water as that of the plots under fertigation (T1, T2, T3, T4 and T6).

Application of hydroponic effluents as per respective fertigation treatments was initiated 2 months after planting. The amount of water/hydroponic effluents applied per day was 1.68 $\mathrm{L} / \mathrm{m}^{2}$ at initial stage, $5.25 \mathrm{~L} / \mathrm{m}^{2}$ at mid interval and $3.15 \mathrm{~L} / \mathrm{m}^{2}$ during the end of the crop cycle respectively. Random samples of undiluted hydroponic effluents used for the experiment were collected and analysed for soluble nutrient content. The Guatemala plant growth was monitored using stem height, canopy development and leaves colour and the fodder yield was recorded for the different treatment plot. The completely randomized design was used with four replicates. Data were statistically analyzed using analysis of variance (ANOVA) according to the statistical package.

\section{Results}

\subsection{Nutrient Content of Hydroponic Effluents}

Random Sample of hydroponic effluents analysed prior to application in field plots is detailed in Table 1. The findings showed that hydroponic effluents contain sufficient amount of nitrate, phosphate, potassium, sodium, calcium and Magnesium and also trace elements such as $\mathrm{Zn}, \mathrm{Fe}, \mathrm{Cu}, \mathrm{Mn}$ and can be reused as a source of plant nutrients for crop production. Given its high soluble nitrate and phosphate content, the 
Table 1 Average nutrient content of hydroponic effluents.

\begin{tabular}{ll}
\hline Soluble nutrients & Composition $(\mathrm{ppm})$ \\
\hline Nitrate & 320.00 \\
Phosphate & 44.02 \\
Sulphate & 38.42 \\
Potassium & 122.00 \\
Sodium & 68.60 \\
Calcium & 88.36 \\
Magnesium & 51.86 \\
Zinc & 0.33 \\
Iron & 0.68 \\
Copper & 0.22 \\
Manganese & 0.12 \\
\hline
\end{tabular}

disposal in the environment can result in environmental pollution.

\subsection{Stem Height}

Guatemala stem heights recorded 3 months after each harvest showed significant difference among the different treatments. The mean fodder stem height was significantly higher in plots irrigated with hydroponic effluents and fertilised using farmers fertiliser practice compared to plots irrigated using only water. Stem height was observed to decrease from $99 \mathrm{~cm}$ to $54 \mathrm{~cm}$ (Table 2) with increaing dilution factor of the hydroponic effluents from 4:0 to $1: 3$ and 0:4. Mean plant stem height recorded in plots treated with farmers fertiliser practice was $103 \mathrm{~cm}$ as compared to $99 \mathrm{~cm}$ in plots under fertigation with undiluted hydroponic effluents.

\subsection{Canopy Development and Leaves Colour}

Figs. 1 and 2 depict the difference in colour of Guatemala fodder under different treatments. It was observed that guatemala crop under fertigation with undiluted hydroponic effluents developed larger plant canopy with dark green colour leaves as compared to small plant canopy with pale green leaves colour as shown in Figs. 1 and 2.

Table 2 Average stem height recorded per treatments.

\begin{tabular}{ll}
\hline Treatment & Average stem height (cm) \\
\hline T1: Fertigation using undiluted hydroponic effluents (4 HE: O Water) & 99 \\
T2: Fertigation using diluted hydroponic effluents (3 HE: 1 Water) & 83 \\
T3: Fertigation using diluted hydroponic effluents (1 HE: 1 Water) & 68 \\
T4: Fertigation using diluted hydroponic effluents (1 HE: 3 Water) & 54 \\
T5: Farmers' fertiliser practice + water & 103 \\
T6: Water nly (O HE: 4 Water)-Control & 39 \\
\hline
\end{tabular}

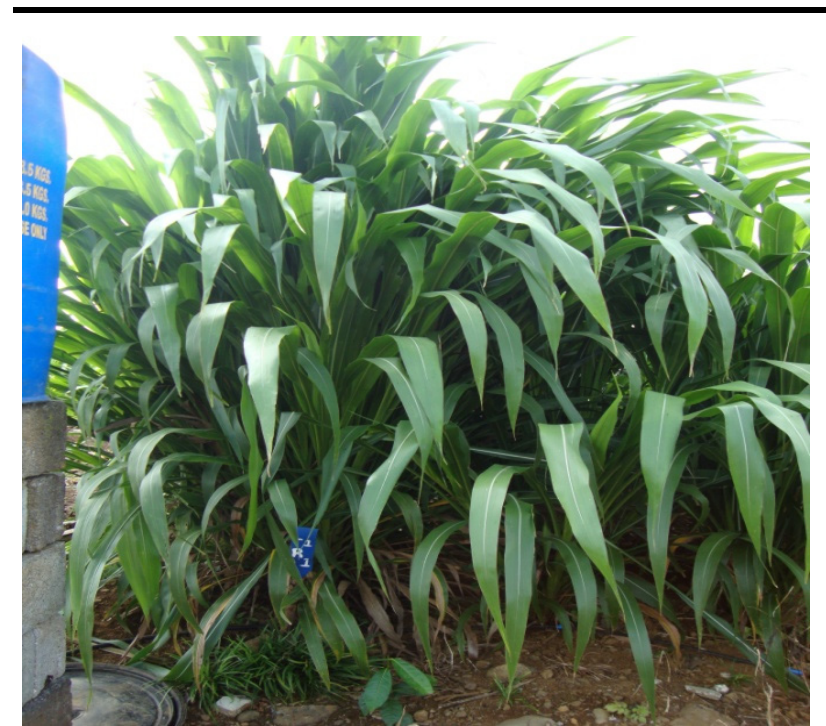

Fig. 1 Guatemala under fertigation with undiluted hydroponic effluents.

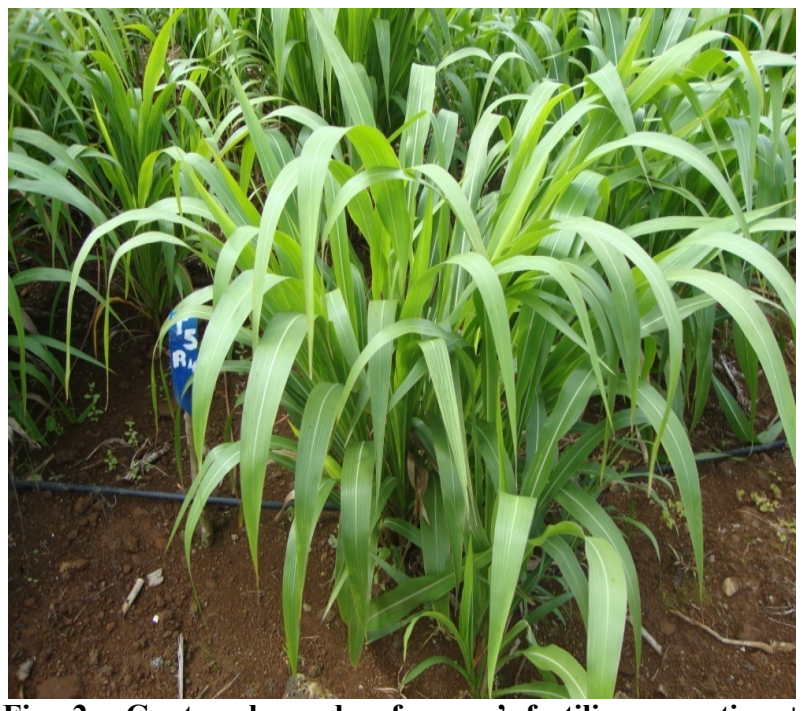

Fig. 2 Guatemala under farmers' fertiliser practice + water. 
It was also noted that, based on the plant canopy development, fodder in plots under fertigation using undiluted hydroponic effluents was observed to reach harvest maturity stage 3 weeks earlier than which in plots treated with water only.

\subsection{Fresh Biomass Yield}

During the phase of the experiment, 6 harvests were conducted and it was observed that the plots treated with farmers fertiliser practice rate gave highest cumulated fresh biomass yield of $300.6 \mathrm{t} / \mathrm{ha}$ following by $250.2 \mathrm{t} / \mathrm{ha}$ recorded in plots under fertigation using undiluted hydroponic effluents (4 HE: O Water) while the plot supplied with only water gave the lowest yield of $130.5 \mathrm{t} / \mathrm{ha}$.

Mean cumulated fresh biomass yield recorded through 6 harvests over the 3 years period (April 2011 to April 2014) in plot fertigated using undiluted hydroponic effluents (4 HE: 0 water) was $250.2 \mathrm{t} / \mathrm{ha}$, followed by $237.0 \mathrm{t} / \mathrm{ha}$ recorded in plots fertigated using hydroponic effluents diluted in ratio of 3HE: 1 water, $222.2 \mathrm{t} / \mathrm{ha}$ recorded in plots fertigated using hydroponic effluents diluted in ratio of 1HE: 1water and $183.0 \mathrm{t} / \mathrm{ha}$ in plots fertigated using hydroponic effluents diluted in ratio of $1 \mathrm{HE}$ : 3 water. It was also noted that, the cumulated yield in plots fertigated using undiluted hydroponic effluents was $16.7 \%$ lower than that recorded in plots conventionally fertilised using farmers fertiliser practice with same water regime.

Cumulated fodder yield increased from $130.5 \mathrm{t} / \mathrm{ha}$ in the control plot irrigated using only water to 183 t/ha in plots under fertigation with1 HE: 3 water to $250.2 \mathrm{t} / \mathrm{ha}$ in plots with undiluted hydroponic effluents (4 HE: 0 water).

This clearly demonstrated that the yield responded positively to an increase in volume of hydroponic effluents in the mixture used for fertigation due to the increase in availability of soluble plant nutrients.

The mean fodder yield recorded per harvest ranged from $21.8 \mathrm{t} / \mathrm{ha}$ in control plot to $50.1 \mathrm{t} / \mathrm{ha}$ recorded in the plot fertiliser using farmers' fertiliser practice (Table 3). It was generally observed that the yield recorded per harvest gradually decreased over time in plots treated with hydroponic effluents diluted in the ratio of 1 HE: 1 Water and 1 HE: 3 water. The yield per harvest in plots under fertigation with $1 \mathrm{HE}: 3$ water was observed to decrease from $40.4 \mathrm{t} / \mathrm{ha}$ in the first harvest to $19.5 \mathrm{t} / \mathrm{ha}$ in the 6th harvest. This may be due to mining of the indigenous soil nutrients over

Table 3 Average fresh biomass yield of Guatemala grass planted in April 2011-April 2014.

\begin{tabular}{|c|c|c|c|c|c|c|c|c|}
\hline \multirow{2}{*}{ Treatments } & 1st harvest & 2nd harvest & 3rd harvest & 4th harvest & 5th harvest & 6th harvest & \multirow{2}{*}{$\begin{array}{l}\text { Mean } \\
\text { /harvest__SD }\end{array}$} & \multirow{2}{*}{$\begin{array}{l}\text { Cumulated } \\
\text { yield(t/ha) }\end{array}$} \\
\hline & Jan. -12 & May -12 & Dec. -12 & Apr. -13 & Nov. -13 & Apr.-14 & & \\
\hline $\begin{array}{l}\text { T1: Fertigation with } \\
\text { undiluted Hydroponic } \\
\text { effluents } \\
\text { (4 HE: O Water) }\end{array}$ & 34.2 & 28.9 & 42.7 & 49.3 & 46.6 & 48.5 & $41.7 \pm 8.4$ & 250.2 \\
\hline $\begin{array}{l}\text { T2: Fertigation using } \\
\text { diluted Hydroponic } \\
\text { effluents } \\
\text { (3 HE: } 1 \text { Water) }\end{array}$ & 41.9 & 40.2 & 33.4 & 44.2 & 47.8 & 29.5 & $39.5 \pm 6.9$ & 237.0 \\
\hline $\begin{array}{l}\text { T3: Fertigation using } \\
\text { diluted Hydroponic } \\
\text { effluents } \\
\text { (1 HE: } 1 \text { Water) }\end{array}$ & 76.3 & 71.4 & 14.4 & 21.9 & 22.7 & 15.5 & $37.0 \pm 28.8$ & 222.2 \\
\hline $\begin{array}{l}\text { T4: Fertigation using } \\
\text { diluted Hydroponic } \\
\text { effluents } \\
\text { (1 HE: } 3 \text { Water) }\end{array}$ & 40.4 & 34.9 & 27.2 & 31.5 & 29.5 & 19.5 & $30.5 \pm 7.1$ & 183.0 \\
\hline $\begin{array}{l}\text { T5: Farmers' fertiliser } \\
\text { practice }+ \text { water }\end{array}$ & 65.5 & 49.8 & 43.8 & 49.6 & 36 & 55.9 & $50.1 \pm 10.1$ & 300.6 \\
\hline $\begin{array}{l}\text { T6: Water only (O HE: } \\
4 \text { Water) - Control T6 }\end{array}$ & 11.4 & 45.2 & 16.2 & 18.6 & 19.9 & 19.2 & $21.8 \pm 11.9$ & 130.5 \\
\hline
\end{tabular}


Table 4 Percentage increase in fresh biomass yield recorded per harvest for each treatment as compared to control plot.

\begin{tabular}{ll}
\hline Treatment & $\%$ increase in yield as compared to control \\
\hline T1: Fertigation using undiluted hydroponic effluents (4 HE: O Water) & 91.7 \\
T2: Fertigation using diluted hydroponic effluents (3 HE: 1 Water) & 81.6 \\
T3: Fertigation using diluted hydroponic effluents (1 HE: 1 Water) & 70.3 \\
T4: Fertigation using diluted hydroponic effluents (1 HE: 3 Water) & 40.2 \\
T5:Farmers' fertiliser practice + water & 130.3 \\
T6: Water only (O HE: 4Water) - Control & Not applicable
\end{tabular}

time due to low inputs in nutrient. Moreover, variation in fodder yield recorded per harvest within one treatment may also be attributed to slow plant growth during the cool winter months and experimental errors.

The use of mineral fertiliser at farmers' fertiliser practice of $475 \mathrm{~kg}$ 17:8:25/ha applied as basal treatment and $235 \mathrm{~kg}$ SoA/ha applied as top dressing

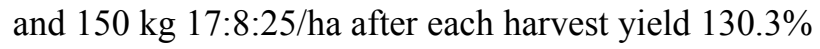
higher yield than the unfertilised plot (treatment 6). Similarly the use of undiluted hydroponic effluents yielded $91.7 \%$ higher biomass yield/harvest as compared to the control plot (Table 4).

\section{Conclusion}

With the rise in water demand the use of wastewater for forage production from hydroponic cultures is well endorsed. The latter could be used in areas where water is a main limiting factor for agricultural production. This study proved that there is potential of using the hydroponic effluents (undiluted or diluted in the ratio of $3 \mathrm{HE}$ : 1 water) in fodder production as it can provide sustainable yield in the range of 39.5-41.7 t/ha per harvest over time. It also indicates that the hydroponic effluent is a good source of nutrients needed for plant growth thereby promoting high yields. The use of hydroponic effluents is also considered as an environmentally sound waste water disposal practice compared to direct disposal into surface or ground water bodies. Hydroponic effluents could in the long term play a significant role in improving water use efficiency.

\section{Acknowledgement}

The present work was partially supported by the Food and Agricultural Research and Extension Institute, Mauritius. The project was also sponsored by the Mauritius Research Council.

\section{References}

[1] Ghazi N. 2011. Green Fodder Production and Water Use Efficiency of Some Forage Crops under Hydroponic Condition. International Scholarly Research Network, ISRN, Agronomy, Volume 2012.

[2] Al-Ghazawi. 2007. "Wastewater Reuse in Agriculture: Global Trends and Local Issues". In Proceedings of the conference Scientific Research on Treated Wastewater Reuse and Biotechnology, 3-22.

[3] Al-Karaki, G. N. 2011. "Utilization of Treated Wastewater for Green Forage Production in A Hydroponic System." Emirates Journal of Food and Agriculture 23: 80-94.

[4] Nsheiwat, Z. B. 2007. "Wastewater Use in Jordan: An Introduction. Wastewater Reuse-Risk Assessment." Decision-Making and Environmental Security. Pol. J. Environ. Stud. 22 (2) (2013): 569-57.

[5] Rakad, A. Ta'any1, Tarek, G. Ammaril, Anwar Jiries, 2013. "Revegetation in Arid Zones: Environmental Impact of Treated Wastewater Irrigation in Al-Karak Province, Jordan.” Pol. J. Environ. Stud. 22 (2): 569-575.

[6] Zekrim, M., Koor, C. J. 1994. "Treated Municipal Wastewater for Citrus Irrigation.” J. Plant Physiol. 17: 693.

[7] Food Security Fund-Strategic Plan 2013-2015, Ministry of Agro-Industry and Food Security, Mauritius.

[8] Manual for Livestock Farmers (Agricultural Research and Extension Unit) 2006. Mauritius. 